\title{
Nota
}

\section{LA SANTIDAD FEMENINA. EL CASO DE TERESA DE JESÚS}

RESUMEN: Esta nota presenta una evaluación del libro Teresa de Jesús. La construcción de la santidad femenina. Este libro entra en el debate historiográfico de los últimos años sobre la santidad femenina religiosa en la época barroca española. Utiliza el caso de Teresa de Jesús como éxito en la consecución de la santidad.

PALABRAS CLAVE: Teresa de Jesús; santidad femenina; monarquía hispánica; corrientes espirituales.

\section{The Female Holiness. The Case of Teresa de Jesús}

ABSTRACT: This note presents an assessment of the book: Teresa de Jesús: La construcción de la santidad femenina. This book deals with the historiographical debate in recent years about female holiness (religious model) in the Spanish Baroque era. It uses the case of Teresa de Jesús as a success in achieving holiness.

KEY WORDS: Teresa de Jesús; female holiness; hispanic monarchy; spiritual movements.

Consejo Superior de Investigaciones Científicas (CSIC):

enriquegarciahernan@gmail.com; ORCID: https://orcid.org/0000-0001-9930-0094 
Alabrús, Rosa M. ${ }^{a}$ y Ricardo García Cárcel. Teresa de Jesús. La construcción de la santidad femenina, Madrid: Cátedra, 2015, 271 pp. ISBN: 978-84-376- 3419-7.

En esta nota voy a valorar la aportación que realizan Rosa M. ${ }^{a}$ Alabrús y Ricardo García Cárcel a la historiografía teresiana. Primero voy a presentar las líneas principales por las que se ha movido la investigación científica de la figura de Teresa de Jesús para, en un segundo paso, sopesar la aportación que supone la monografía objeto de este comentario.

\section{EL CONTEXTO: LÍNEAS FUNDAMENTALES DE LOS ESTUDIOS TERESIANOS}

De Teresa de Jesús sabemos mucho. Nace en 1515 en Ávila, muere con 67 años, en 1582, en Alba de Tormes. A los 20 años ya es religiosa, así que hace 47 años de vida activa y contemplativa en el Carmelo, como reformadora o fundadora. Beatificada en 1614 y canonizada en 1622, alcanza más fama en 1970 como Doctora de la Iglesia. También, gracias a ella, se ha debatido, se debate y se debatirá del eterno problema entre lo que se sabe por amor y lo que se aprende estudiando, en esa titánica lucha entre dos polos que se intercomunican. Pero ante todo hay que decir que es una desconocida desde un punto de visto histórico-científico. Hay que acercarse a su persona a través de tres fuentes: escritos, epistolario y testimonios, especialmente en sus procesos de canonización. Pues bien, de sus escritos - dejando de lado la originalidad absoluta- es difícil extraer los influjos de sus lecturas — sin duda Francisco de Osuna- y de sus conversaciones - al menos importantes las de Domingo Báñez y las de Francisco de Borja-. La edición de sus obras de 1588 mucho debe a fray Luis de León. Recuperar el original exacto de la Madre en casi todas sus obras es bastante complicado por la autocensura y censuras colaterales; ahí, están, por ejemplo, las censuras a nombres entonces sospechosos como Ignacio de Loyola y Francisco de Borja. En cuanto a sus cartas, estimadas en unas 25.000 , sólo se conocen 451 y 24 fragmentos sin datar - pocas originales-; y de éstas 110 son para Gracián de la Madre de Dios y la mayoría del periodo 1576-1582. A mi juicio — siendo lo más importante históricamente- no se han aprovechado suficientemente. Se ha de hacer constar, asimismo, que — dejando las muy parciales 
de copias de los siglos XVII a XIX - se comienzan a conocer a partir de 1922. Y respecto a los procesos diocesanos -el primero en Salamanca en 1591-, hay que, por metodología científica, como poco, ponerlos en cuarentena. En 1935 se editan 229 testimonios, en 2008 se añaden 110, y en 2016-2017 se llegan hasta los 751, en seis volúmenes, pero todavía quedan muchos por editarse, y por encontrar 17 procesos perdidos, entre ellos el quizá más importante de Toledo. Por tanto, si miramos sólo a las fuentes originales - excluyo el mayor o menor acierto en la edición crítica-, la Madre Teresa sigue siendo un enigma histórico ${ }^{1}$.

Es posible que aparezcan nuevas cartas - estoy convencido de ello-, y que se publiquen más documentos de los procesos. Ahora bien, toda biografía que pretenda adentrarse en su personalidad, con una metodología científica, tiene por fuerza que acudir a fuentes colaterales, diría de contexto, al ritmo de los usos y modas imperantes, lo cual exige un dominio grande del periodo, y no basta con ser teresianista. Cada época se pregunta qué puede aportar la Madre Teresa a nuestro tiempo, y como el actual es vertiginoso, cada año habría que replantearse la vinculación de la Madre Teresa con nuestro presente. En general casi todas las biografías resaltan aspectos distintos según la disciplina que se utilice y el tiempo en el que se escribe. Así las primeras, hagiográficas, trastocan tanto la realidad que hoy ya no reconocemos en casi nada en ellas a la Madre Teresa. Los que ven desde las emociones no quedan nunca defraudados, y - aunque cada tiempo entiende de un modo distinto el humor-Teresa de Jesús nos alegra siempre. Los que buscan una explicación psicosomática de la vida también pueden encontrar en ella el influjo de su extraña y sorprendente vida. Y los estudiosos de la mística tienen un campo inmenso donde explayarse a sus anchas; y los de la literatura espiritual lo mismo, etc. Hoy día una biografía de fondo debería buscar la emergencia de su sistema complejo, como diría Edgar Morin. Quiero decir que - dadas las limitaciones heurísticas - es preciso un proyecto científico transdisciplinar sin prejuicios ni miedos.

El duque de Alba no duda un instante en librar miles de ducados para sostener los procesos de canonización y biografías, como las de Francisco de Ribera y Diego de Yepes. Desde entonces la Casa de Alba procura proteger los estudios teresianos. Y quizá por esto el duque de Alba, Jacobo

\footnotetext{
1 Julen Urkiza Txakartegi. "La canonización de santa Teresa de Jesús". Anuario de historia de la Iglesia 29 (2020): 229-260.
} 
Fitz-James Stuart, como director de la Real Academia de la Historia, alienta con energía los estudios teresianos, especialmente de Miguel Mir. Así surgieron importantes estudios que abrieron camino a pesar de las limitaciones. Son preciosos escritos de autores como Morel-Fatio, Asín Palacios, Américo Castro, Crisógono de Jesús Sacramentado, Menéndez Pidal, Silverio de Santa Teresa, etc. De resultas de la nueva documentación publicada — como los inquisitoriales en 1972- viene la gran biografía de Efrén de la Madre de Dios y de Steggink, en 1977, el clásico Tiempo y vida de santa Teresa. Y también gracias a los duques de Alba se han publicado los nuevos testimonios de los procesos a la sombra del V Centenario de su nacimiento.

Hoy día contamos con importantes estudios sobre Teresa de Jesús, tanto dentro de los Carmelitas — Tomás Álvarez- como fuera - Rosa Rossi y Josef Pérez- . La historiografía reciente está marcada por distintos enfoques metodológicos. Quien marca la línea de salida es Teófanes Egido en 1981 con el artículo "El tratamiento histórico de Santa Teresa. Inercias y revisiones", en el libro por él dirigido Perfil histórico de Santa Teresa. Cuando se relee este libro da la sensación de que ha sido como predicar en el desierto. Luego vienen acertados trabajos como el de las redes o circulación de élites que crean cultura e identidades, con precursores como Aurora Egido sobre los interlocutores letrados². También los de la cultura inmaterial o los de la cultura escrita. No cabe duda de que se llevan la victoria los interminables y a veces pesados estudios desde la historia de la espiritualidad de teresianistas. Hoy día se pone mucho el acento en los distintos modelos de santidad femenina, así en los últimos cuarenta años —especialmente desde el centenario de su muerte- asistimos a un florecimiento de los estudios sobre la mujer espiritual en la Edad Moderna en España. La lista de autores, libros, congresos, artículos, es muy larga ${ }^{3}$. Al principio no han tenido gran soporte metodológi-

2 Tomás Álvarez Fernández. Teresa de Jesús. Burgos: 2001; Rosa Rossi. Teresa de Ávila: biografía de una escritora. Madrid: 1993; Joseph Pérez. Teresa de Ávila y la España de su tiempo. Madrid: 2007. Aurora Egido. "Santa Teresa contra los letrados: los interlocutores de su obra”. Criticón 20 (1982): 85-121.

3 Isabelle Poutrin. "Las mujeres en el siglo de las reformas religiosas". En Historia del cristianismo, coordinado por Antonio Luis Cortés Peña, vol. 3, 509-550. Madrid: 2006. Ana Morte Acín. "Mujeres ejemplares en los modelos de santidad femenina barrocos”. En De la tierra al cielo: Lineas recientes de investigación en historia moderna, coordinado por Eliseo Serrano Martín, vol. 2, 935-948. Zaragoza: 2012. Jimena 
co, quizá acomplejados por los que se han acercado a la mujer religiosa desde la literatura y los biógrafos poco documentados, en una especie de competición por conquistar un terreno entre filólogos, sociólogos, historiadores, teólogos, etc. De ahí que historiadores de peso consideren la biografía espiritual — también la de Teresa de Jesús — un género literario e incluso un suicidio académico. Pero algunos han sabido posicionarse, cabe destacar a Poutrin, Atienza y Acín.

Estos estudios han ido marcando una metodología y unos objetivos. Merecen la pena señalar para la Edad Media a Régine Pernoud, Reyna Pastor de Togneri, Georges Duby y recientemente, entre otras, a María del Mar Graña Cid. Han tenido que hacerse hueco entre los estudios de género o los que postulan una teología espiritual femenina y otros incluso feminista. Es verdad que se han acercado a la cuestión de la mujer desde distintas ópticas, porque ciertamente las limitaciones a su actuación femenina no se limitan a la espiritual, ahí está el terreno de las ciencias o de la producción artística y literaria, historiografía que también hay que tener en cuenta. El tema estrella ha sido el de las beatas y alumbradas por el problema que hereda la Madre Teresa sobre si las mujeres pueden o no hacer oración mental, y sobre todo por la crisis inquisitorial de 1559. Hay dos momentos históricos que cambian por completo la percepción de la santidad femenina en el tránsito de la Edad Media a la Edad Moderna. Me refiero, primero, a Juana de Arco, rehabilitada por Calixto III cinco lustros después de su muerte, en 1456. Se da la razón a una mujer, se reconocen sus visiones y se admite que no se puede obrar contra la conciencia. Otro papa español de la misma familia no hizo lo mismo con Savonarola. Estas posiciones tienen influjo — decisivo- de cara a los orígenes del luteranismo. La santa de Francia es canonizada en 1920 y se recupera su figura de modo extraordinario, al ponerse en alza el valor de la conciencia ante una Francia ocupada y luego liberada ${ }^{4}$. El

Gamba Corradine. "Models of Female Spirituality in Sixteenth-century Spain". En Gender and Exemplarity in Medieval and Early Modern Spain, coordinado por María Morrás Ruiz-Falcó, Rebeca Sanmartín Bastida y Yonsoo Kim, 163-189. Leyden: 2020.

${ }^{4}$ Gerd Krumeich. "Condena y rehabilitación de Juana de Arco. El proceso y la historia de su influencia (1431-1456)". En Los grandes procesos: derecho y poder en la Historia, editado por Alexander Demandt, 112-124. Barcelona: 1993. Pablo Acosta García. "Santas y marcadas: itinerarios de lectura modélicos en las obras de las místicas bajomedievales impresas por Cisneros". Hispania sacra 72, n. ${ }^{\circ} 145$ (2020): 137-150. 
segundo momento histórico es el de la fe ciega de Cisneros en las mujeres religiosas cuando todavía no lo son. Sólo por esto el cardenal merece mayor atención, porque abre un surco de originalidad y creación artística femenina que queda medio sepultado en 1559.

Los trabajos de investigación sobre la santidad femenina, desde la teología, literatura o la historia, han sido a veces reorientados desde la experiencia de Teófanes Egido y de otros ${ }^{5}$. Brillan hoy los trabajos de Bilinkoff, Weber, Mujica, Ahlgren, Slade. Pero vendrán más, con nuevas perspectivas y nuevas metodologías. En el V Centenario se han retomado los estudios y lógicamente se han abierto líneas de investigación y nuevas metodologías ${ }^{6}$. En España, Javier Burrieza y Emilio Callado han formado un tándem interesante, favoreciendo encuentros y obras colectivas, sembrando a la espera de que venga la cosecha ${ }^{7}$. En este contexto es cuando nace el libro que deseo comentar brevemente, el de Rosa María Alabrús y Ricardo García Cárcel sobre la construcción de la santidad femenina a través de Teresa de Jesús. Rosa María Alabrús, que también se ha centrado en espiritualidad femenina, ha continuado publicando sobre este tema ${ }^{8}$. Ricardo García Cárcel es muy conocido entre los modernistas, una autoridad en historia cultural y religiosa.

${ }^{5}$ Proyecto "La construcción de la santidad femenina y el discurso visionario (siglos XV-XVII): Análisis y recuperación de la escritura conventual”. Teófanes Egido López. "Santa Teresa y las tendencias de la historiografía actual". Teresianum 33, n. ${ }^{\circ}$ 1-2 (1982): 159-180. Teófanes Egido López. "La madre Teresa de Jesús, mujer y espiritual en tiempos de Contrarreforma". En El alma de las mujeres. Ámbitos de espiritualidad femenina en la modernidad (siglos XVI-XVIII), coordinado por Javier Burrieza Sánchez, 23-38. Valladolid: 2015. Viviendo sin vivir en mí: estudios en torno a Teresa de Jesús en el V Centenario de su nacimiento, coordinado por Emilio Callado Estela. Madrid: 2015.

6 Teresa de Jesús, V centenario de su nacimiento historia, literatura y pensamiento, coordinado por Jesús García Rojo. Salamanca: 2015. Ángela Atienza López. "En torno a santa Teresa y su proyección. Historia y memoria en 2015”. Hispania sacra 67, n. ${ }^{\circ} 136$ (2015): 391-399.

7 Jodi Bilinkoff. Ávila de Santa Teresa: la reforma religiosa en una ciudad del siglo XVI. Madrid: 1993. A. Weber. Teresa of Avila and the Rhetoric of Femininity. Princeton: 1990. Carole Slade. Teresa of Avila. Author of a Heroic Life. Berkeley: 1995. Gillian Ahlgren. Teresa of Avila and the Politics of Sanctity. Ithaca: 1996. Barbara Mujica. Teresa of Avila: Lettered Woman. Nashville: 2009.

${ }^{8}$ Rosa María Alabrús. "La reputación de la monarquía hispánica a través del proceso de beatificación y canonización de Teresa de Jesús”. En La Reputación: quête individuelle et aspiration collective dans l'Espagne des Habsbourg: Hommage à la 


\section{APORTACIONES SIGNIFICATIVAS A LOS ESTUDIOS TERESIA- NOS DE LA OBRA DE ALABRÚS Y GARCÍA CÁRCEL}

Se trata de un libro que ha tenido importantes reseñas y que creo merece una mayor atención, toda vez que Teófanes Egido lo ha calificado como "un libro así, tan serio y rebosante de logros y de sugerencias» ${ }^{9}$. Desde mi punto de vista este libro pone un contexto necesario y abre líneas de investigación sobre Teresa de Jesús que sirven de cara a una nueva gran biografía, que ya hace tiempo se espera. La principal virtud de este libro es que, además del contexto, entiende muy bien la vida religiosa y lo que denomina construcción de la santidad femenina como proceso histórico. Los autores básicamente afirman que la originalidad de Teresa de Jesús está en saber conjugar elementos contrapuestos, realista y fantasiosa. Al leer esto viene enseguida a la mente cuando en el Camino de Perfección dice que Dios nos enseña que hay dos mundos: uno eterno y otro soñado.

Los autores dicen que pretenden sólo hacer reflexiones sobre la construcción de la santidad, entendida como ejemplaridad pública en la España del Barroco. Una cosa es cómo uno se hace santo (Camino de Perfección 12), y otra es el proceso por el cual otros te hacen santo (procesos de canonización). Los autores optan por la segunda, terreno también minado, pero más seguro para ellos. La Madre anima a sus hijas a que sean santas, no a que alguien después reconstruya su santidad, y la clave es la oración mental. Ante el miedo inquisitorial dice que los herejes lo son no por hacer oración, sino por «distraerse». El otro aspecto es el específico de la santidad femenina religiosa como estereotipo canónico que emerge de aguas algo pantanosas -no entran en lo específico carmelitano-. Parece así que hay una santidad masculina preponderante y una femenina que se abre paso a través de Teresa de Jesús. La pregunta es por qué ella es santa y otras no. El método que han seguido es

professeure Araceli Guillaume-Alonso, dirigido por Béatrice Pérez, 151-163. Sorbonne: 2018. Rosa María Alabrús. "Visiones y sueños de las monjas del barroco español". E-Spania: Revue électronique d'études hispaniques médiévales 21 (2015).

9 Teófanes Egido López. "Teresa de Jesús y Catalina de Cardona: rigores y santidad”. En Pasados y presente: estudios para el profesor Ricardo García Cárcel, coordinado por Rosa María Albrús, José Luis Betrán Moya, Francisco Javier Burgos Rincón, Bernat Hernández, Doris Moreno y Manuel Peña Díaz, 629-642. Barcelona: 2020. Las recensiones en: Facundo Sebastián Macías. Revista Rey Desnudo: Revista de Libros 5, n. 9 (2016): 29-36. Alison Weber. Cuadernos de Historia Moderna 41, n. ${ }^{\circ} 1$ (2016): 225-228. Henar Pizarro Llorente. Hispania 77, n. ${ }^{\circ} 256$ (2017): 546-548. 
el estudio de las biografías y autobiografías de monjas y en un segundo paso el proceso histórico por la canonización - aunque no se detienen mucho en su doctorado de la Iglesia-. Dejando de lado la espiritualidad laical de santidad femenina - como optan los autores- habría que ver el Index ac status sanctorum (Roma 1999) y localizar todos los procesos incoados, de venerables, beatas y santas anteriores y contemporáneas a la Madre Teresa, también de las no españolas, e incluso de varones, porque ciertamente hay otros muchos Juan de Ávila que esperan el milagro. Así habría que preguntarse sobre cuál es el modelo de santidad femenina de la Madre; evidentemente pesa mucho Catalina de Siena. Por otro lado, se preguntan por el éxito de la Madre Teresa frente a otras como Hipólita de Rocabertí. Ya el polígrafo sevillano Nicolás Antonio de finales del siglo XVII dice de la Santa que constituyó la admiración de todos en la época de sus padres. Mientras que de Rocabertí señala que ha escrito mucho, pero nada añade de su personalidad. Es decir, no caló entre sus contemporáneos. Esto lo explican muy bien los autores.

El capítulo I analiza lo que han llamado la fábrica de los santos. Son unas apretadas páginas que encierran un haz de ideas a tener muy en cuenta. La primera es que en las causas hay unas preguntas clave sobre las virtudes y a través de las respuestas se compone la positio que servirá para hacer la biografía oficial. Por tanto, lo que hay que estudiar es quién es el postulador (fray Domingo Jesús María), y cómo llega a reconstruir la biografía heroica y tratar de limpiarla de la hagiografía. Y es aquí donde aparece lo que con razón llaman la contradicción de atender la demanda de santos y la prevención ante una instrumentalización de la santidad. También hay que aclarar los motivos por los que no han salido adelante los procesos de compañeras de la Madre Teresa. En este sentido se enmarcan lo que llaman prevenciones frente a la santidad femenina, en especial el «reverso caricaturesco» de Catalina de Cardona, y profundizar en la ilusión y embaucamiento. También es importante la conexión entre política y mística, y cómo las monjas influyeron en algunas decisiones de los monarcas, como María de Ágreda, María de la Visitación, Marina de Escobar, Luisa de Carvajal, etc. Otra línea de investigación que hay que continuar es la relación con la Compañía de Jesús, en la línea de los estudios de Teófanes Egido y Javier Burrieza ${ }^{10}$. Creo que

10 Teófanes Egido López. “La principal ayuda que he tenido'. Santa Teresa y los de la Compañía de Jesús”. Manresa 87, n. ${ }^{\circ} 342$ (2015): 5-16. 
habría que repensar si los dos encuentros de abril de 1557 de Borja con la Madre Teresa tienen más importancia, como ha señalado Santiago La Parra. Cuenta ella en su Vida que le dio la medicina y consejo, «que hace mucho en esto la experiencia» ${ }^{11}$. Todavía (Camino de Perfección, capítulo 31) vuelve a hablar de Borja a propósito de la unidad entre vida activa y vida contemplativa, que puede pasar, «era muy posible, que a él le acaecía». Podría preguntarse si traslada la espiritualidad femenina de los Ejercicios, como ha rastreado María Prieto Ursúa con sus «Claves de psicología y espiritualidad femenina en los Ejercicios Espirituales» ${ }^{12}$. Y tirando de este hilo, faltaría un recorrido lo más completo posible de todos sus confesores para encontrar la «complejidad emergente».

El capítulo II explora el canon de santidad femenina. Es muy atinado el acentuar la vocación de escritora de la Madre y que para ser buena escritora hay que ser buena lectora. Por tanto, se debe profundizar más en sus lecturas, y encontrar la mano de Báñez, fray Luis de León, Juan de Ávila y de otros en sus escritos, para que brille sólo la de ella. En este sentido hay que trabajar a fondo en el libro de la Vida, porque es en realidad una meditación larga. No sería necesario, me pregunto, una biografía de la Madre que fuera en realidad la historia de esa meditación. Lo digo porque los autores apuntan a una «definitiva conversión» tras un encuentro con la Pasión de Cristo, precisamente lo que le aconsejó Borja. Esta historia sería básicamente tratar de extraer de la Vida lo que tenía que haber sido su diario espiritual. Respecto al arquetipo de su santidad - dejando de lado el misterio de los éxtasis, arrobamientos, demonios, miedos, rigores, etc.- y la desconexión de la misma respecto a sus hijas, no creo que fuera culpa sólo de ellas, porque la caída de Gracián y la llegada de Doria cambia todo, se va a la ultraortodoxia, rigorismo, y desorientación, acaso por encasillar tridentinamente los dones de Dios y, sobre todo, por la división entre calzados y descalzos. Estoy de acuerdo en que les apremió demasiado la santidad de puertas adentro, pero se podría achacar a un error de la Madre, porque ella no pidió que la imitaran, sino que imitaran a Jesús en el camino seguro de la oración. Teresa de Jesús es modelo, pero queda prisionera parcialmente no sólo de sus monjas, sino

11 Santiago La Parra López. "Francisco de Borja en el espejo de Teresa de Jesús (vidas paralelas unidas por la modernidad)". Studia historica. Historia moderna 39, n. ${ }^{\circ} 1$ (2017): 327-367.

12 Manresa 90, n. 357 (2018): 335-346. 
de los letrados. Así hoy día —si la apartamos de esos encorsetamientoses modelo para todos -incluso no cristianos-, hombres y mujeres, y de todos los tiempos, porque se convierte en tesoro de la humanidad. Una línea por explorar es la de los carmelitas que llevan el cristianismo a las mujeres safávidas. Habría que preguntarse, ya lo hizo Asín Palacios, sobre Teresa y el sufismo, y ver lo que hicieron los carmelitas en Persia, en la línea de Ana María Salto Sánchez del Corral y Rudi Matthee.

El capítulo III es el más centrado en la Madre y una obra de arte de contextualización de la gran crisis de 1559 y de su éxito póstumo. En realidad, dicen más de lo que está escrito, hay insinuaciones interesantes. Podría decir muchas, pero por brevedad me centro en dos. La primera es lo que denominan "calvario de inquietudes económicas». Es urgente analizar a fondo la economía de la Madre y de los conventos, utilizar los diversos fondos documentales sobre esto, desde la historia de la economía. Todo el que ha estudiado la vida de los santos de este periodo conoce la importancia de la cuestión económica, no sólo para vivir sin más, sino para entender qué es la pobreza, y si hay una pobreza femenina distinta de la masculina. La segunda es el problema de la Inquisición de 1576. Creo que hay que utilizar más las delaciones y censuras que ha editado Llamas - no están todas- y que no aparecen entre los testigos de los procesos de canonización.

El capítulo IV es sobre cómo entienden los autores la santidad de Teresa de Jesús, es decir, el funambulismo. Explican muy bien el proceso por el que presenta un modelo femenino frente a la misoginia de modo estratégico (Camino de Perfección 4). También entran en el tema conocido ya de la limpieza de sangre. En este terreno habría que preguntarse sobre las mujeres conversas, su espiritualidad, como la madre de Vives. A la Madre Teresa podríamos decir que no le importa nada la honra. Estoy de acuerdo en que parece que el problema no va con ella. Más importante es la relación de Teresa con el protestantismo, y aquí habría que trabajar más. Es verdad que Teresa apenas conoce la Biblia, es más por oídas, no sabe latín, pero sin embargo tiene lo que algunos jesuitas llaman olfato católico. El libro de Manuel Peña ${ }^{13}$ ayuda a comprender mejor esto. Podía haber sido una beata más, acaso con cierto alumbradismo. ¿Qué hizo que cayera del lado católico? En 1559 apenas nadie sabe con certeza qué es ser católico, incluso hoy casi pasa lo mismo con las rehabilitaciones

${ }^{13}$ Escribir y prohibir: inquisición y censura en los Siglos de Oro. Madrid: 2015. 
de Lutero, porque ¿quién sabe de verdad con certeza cómo se produce la redención? Los autores se extienden bastante en un terreno que dominan y prácticamente acotan definitivamente sobre el que hay que trabajar. Lo que es urgentísimo solucionar es la razón de que saliera indemne de la Inquisición, porque hay — si vamos a los originales - unas afirmaciones muy sospechosas para esos hombres. ¿Acaso tiene amigos dentro? Quizá hay que trabajar más la biografía de Gracián y su conexión con la Madre. Son escritos depurados, son reafirmación católica, que aparecen claramente en el Camino, de fidelidad absoluta a la Iglesia. Hay aquí también mucho que trabajar sobre el sentido del amor teresiano, del Capitán del amor, de la bandera de la Cruz, del alférez que no lucha, pero se mantiene firme. En fin, que no se ha dicho todo sobre el amor y un careo con el amor en autores protestantes es necesario. Por sugerir algo, hay un punto en común, que es Erasmo y Vives. De ahí, unos van por un lado y otros por otro.

El capítulo V y último es sobre la red Teresa. Solo hay 110 destinatarios de sus cartas, pero si hacemos un conteo con las cartas que deberían haber sobrevivido, ese número superaría los dos mil. Habría que trabajar más a sus secretarias, apuntar nuevos destinatarios para intentar encontrar nuevas cartas. Los autores explican bien el contexto de la familia, los amigos y las monjas. ¿No habría también otra red? Sería la de los «enemigos», es decir, los delatores, acusadores. Los que no la entienden y tienen que seguir diciendo algo para que se note. Terminan con unas reflexiones que ciertamente hacen pensar, pero sobre todo son un incentivo a que venga pronto una biografía que no deje de lado la mujer que fue - los autores hablan de tercer icono-y que sigue siendo modelo para hoy y será para mañana.

Hay que felicitar de verdad a los autores y llamar la atención sobre la actualidad del reclamo de la Madre a las religiosas - que sirve para todas las mujeres y todos los varones - de hacer oración, como agua de vida, pase lo que pase (Camino de Perfección 21): «importa mucho, y el todo, una grande y muy determinada determinación de no parar hasta llegar a ella, venga lo que viniere, suceda lo que sucediere, trabájese lo que se trabajare, murmure quien murmurare, siquiera llegue allá, siquiera se muera en el camino o no tenga corazón para los trabajos que hay en él, siquiera se hunda el mundo». 


\section{REFERENCIAS}

Acosta García, Pablo. "Santas y marcadas: itinerarios de lectura modélicos en las obras de las místicas bajomedievales impresas por Cisneros". Hispania sacra 72, n. ${ }^{\circ} 145$ (2020): 137-150. https://doi.org/10.3989/hs.2020.011

Ahlgren, Gillian. Teresa of Avila and the Politics of Sanctity. Ithaca: 1996. Alabrús, Rosa María. "La reputación de la monarquía hispánica a través del proceso de beatificación y canonización de Teresa de Jesús". En La Reputación: quête individuelle et aspiration collective dans l'Espagne des Habsbourg: Hommage à la professeure Araceli Guillaume-Alonso, dirigido por Béatrice Pérez, 151-163. Sorbonne: 2018.

Alabrús, Rosa María. "Visiones y sueños de las monjas del barroco español". E-Spania: Revue électronique d'études hispaniques médiévales 21 (2015). https://doi.org/10.4000/e-spania.24474

Álvarez Fernández, Tomás. Teresa de Jesús. Burgos: 2001.

Atienza López, Ángela. "En torno a santa Teresa y su proyección. Historia y memoria en 2015". Hispania sacra 67, n. ${ }^{\circ} 136$ (2015): 391-399. https:// doi.org/10.3989/hs.2015.011

Bilinkoff, Jodi. Ávila de Santa Teresa: la reforma religiosa en una ciudad del siglo XVI. Madrid: 1993.

Egido López, Teófanes. “La principal ayuda que he tenido'. Santa Teresa y los de la Compañía de Jesús”. Manresa 87, n. ${ }^{\circ} 342$ (2015): 5-16.

Egido López, Teófanes. "La madre Teresa de Jesús, mujer y espiritual en tiempos de Contrarreforma". En El alma de las mujeres. Ámbitos de espiritualidad femenina en la modernidad (siglos XVI-XVIII), coordinado por Javier Burrieza Sánchez, 23-38. Valladolid: 2015.

Egido López, Teófanes. "Santa Teresa y las tendencias de la historiografía actual". Teresianum 33, n. ${ }^{\circ}$ 1-2 (1982): 159-180.

Egido López, Teófanes. “Teresa de Jesús y Catalina de Cardona: rigores y santidad". En Pasados y presente: estudios para el profesor Ricardo García Cárcel, coordinado por Rosa María Albrús, José Luis Betrán Moya, Francisco Javier Burgos Rincón, Bernat Hernández, Doris Moreno y Manuel Peña Díaz, 629-642, Barcelona: 2020.

Egido, Aurora. "Santa Teresa contra los letrados: los interlocutores de su obra”. Criticón 20 (1982): 85-121.

Gamba Corradine, Jimena. "Models of Female Spirituality in Sixteenth-century Spain". En Gender and Exemplarity in Medieval and Early Modern Spain, coordinado por María Morrás Ruiz-Falcó, Rebeca Sanmartín Bastida, y Yonsoo Kim, 163-189. Leyden: 2020. 
Krumeich, Gerd. "Condena y rehabilitación de Juana de Arco. El proceso y la historia de su influencia (1431-1456)". En Los grandes procesos: derecho y poder en la Historia, editado por Alexander Demandt, 112124. Barcelona: 1993.

La Parra López, Santiago. "Francisco de Borja en el espejo de Teresa de Jesús (vidas paralelas unidas por la modernidad)". Studia historica. Historia moderna 39, n. ${ }^{\circ} 1$ (2017): 327-367. https://doi.org/10.14201/ shhmo2017391327367

Morte Acín, Ana. "Mujeres ejemplares en los modelos de santidad femenina barrocos". En De la tierra al cielo: Líneas recientes de investigación en historia moderna, coordinado por Eliseo Serrano Martín. Vol. 2, 935-948. Zaragoza: 2012.

Mujica, Barbara. Teresa of Avila: Lettered Woman. Nashville: 2009.

Peña, Manuel. Escribir y prohibir: inquisición y censura en los Siglos de Oro. Madrid: 2015.

Pérez, Joseph. Teresa de Ávila y la España de su tiempo. Madrid: 2007.

Pizarro Llorente, Henar. Hispania 77, n. ${ }^{\circ} 256$ (2017): 546-548.

Poutrin, Isabelle. "Las mujeres en el siglo de las reformas religiosas". En Historia del cristianismo, coordinado por Antonio Luis Cortés Peña. Vol. 3, 509-550. Madrid: 2006.

Prieto Ursúa, María. "Claves de psicología y espiritualidad femenina en los Ejercicios Espirituales”. Manresa 90, n. 357 (2018): 335-346.

Proyecto "La construcción de la santidad femenina y el discurso visionario (siglos XV-XVII): Análisis y recuperación de la escritura conventual".

Rossi, Rosa. Teresa de Ávila: biografía de una escritora. Madrid: 1993.

Sebastián Macías, Facundo. Revista Rey Desnudo: Revista de Libros 5, n. ${ }^{\circ} 9$ (2016): 29-36.

Slade, Carole. Teresa of Avila. Author of a Heroic Life. Berkeley: 1995.

Teresa de Jesús, $V$ centenario de su nacimiento historia, literatura y pensamiento, coordinado por Jesús García Rojo, Salamanca: 2015.

Urkiza Txakartegi. Julen. "La canonización de santa Teresa de Jesús". Anuario de historia de la Iglesia 29 (2020): 229-260.

Viviendo sin vivir en mí: estudios en torno a Teresa de Jesús en el V Centenario de su nacimiento, coordinado por Emilio Callado Estela. Madrid: 2015.

Weber, Alison. Teresa of Avila and the Rhetoric of Femininity. Princeton: 1990.

Weber, Alison. Cuadernos de Historia Moderna 41, n. ${ }^{\circ} 1$ (2016): 225-228. 
